Article

\title{
Diffusion Assessment of Cortical Changes, Induced by Traumatic Spinal Cord Injury
}

\author{
Peng Sun ${ }^{1}$, Rory K. J. Murphy ${ }^{2}$, Paul Gamble ${ }^{3}$, Ajit George ${ }^{1}$, Sheng-Kwei Song ${ }^{1}$ \\ and Wilson Z. Ray ${ }^{2, *}$ \\ 1 Department of Radiology, Washington University School of Medicine, St. Louis, MO 63110, USA; \\ pengsun@wustl.edu (P.S.); ajitgeorge@wustl.edu (A.G.); ssong@wustl.edu (S.-K.S.) \\ 2 Department of Neurological Surgery, Washington University School of Medicine, St. Louis, MO 63110, USA; \\ murphyr@wudosis.wustl.edu \\ 3 School of Medicine, Washington University, St. Louis, MO 63110, USA; gamblep@wusm.wustl.edu \\ * Correspondence: rayz@wudosis.wustl.edu; Tel.: +1-314-747-6145
}

Academic Editor: Raymond J. Grill

Received: 8 September 2016; Accepted: 14 February 2017; Published: 17 February 2017

\begin{abstract}
Promising treatments are being developed to promote functional recovery after spinal cord injury (SCI). Magnetic resonance imaging, specifically Diffusion Tensor Imaging (DTI) has been shown to non-invasively measure both axonal and myelin integrity following traumatic brain and SCI. A novel data-driven model-selection algorithm known as Diffusion Basis Spectrum Imaging (DBSI) has been proposed to more accurately delineate white matter injury. The objective of this study was to investigate whether DTI/DBSI changes that extend to level of the cerebral peduncle and internal capsule following a SCI could be correlated with clinical function. A prospective non-randomized cohort of 23 patients with chronic spinal cord injuries and 17 control subjects underwent cranial diffusion weighted imaging, followed by whole brain DTI and DBSI computations. Region-based analyses were performed on cerebral peduncle and internal capsule. Three subgroups of patients were included in the region-based analysis. Tract-Based Spatial Statistics (TBSS) was also applied to allow whole-brain white matter analysis between controls and all patients. Functional assessments were made using International Standards for Neurological Classification of Spinal Cord Injury (ISNCSCI) as modified by the American Spinal Injury Association (ASIA) Scale. Whole brain white matter analysis using TBSS finds no statistical difference between controls and all patients. Only cervical ASIA A/B patients in cerebral peduncle showed differences from controls in DTI and DBSI results with region-based analysis. Cervical ASIA A/B SCI patients had higher levels of axonal injury and edema/tissue loss as measured by DBSI at the level of the cerebral peduncle. DTI Fractional Anisotropy (FA), Axial Diffusivity (AD) and Radial Diffusivity (RD) was able to detect differences in cervical ASIA A/B patients, but were non-specific to pathologies. Increased water fraction indicated by DBSI non-restricted isotropic diffusion fraction in the cerebral peduncle, explains the simultaneously increased DTI AD and DTI RD values. Our results further demonstrate the utility of DTI to detect disruption in axonal integrity in white matter, yet a clear shortcoming in differentiating true axonal injury from inflammation/tissue loss. Our results suggest a preservation of axonal integrity at the cortical level and has implications for future regenerative clinical trials.
\end{abstract}

Keywords: magnetic resonance imaging; diffusion tensor imaging; diffusion basis spectrum imaging; spinal cord injury

\section{Introduction}

Spinal cord injury (SCI) is a significant public health problem. Currently, 253,000 people in the United States are living with SCI, while 11,000 Americans are hospitalized for SCI each year [1]. 
Annually, \$9.7 billion dollars are being spent on SCI research and patient care. A major shortcoming limiting efforts to improve the treatment of SCI is the lack of quantifiable metrics on which to base clinical decisions. Biomarkers are emerging in many fields as valuable predictors of a patient's clinical course and response to therapy. Diffusion tensor imaging (DTI) has been demonstrated to noninvasively reflect the progression of white matter tract damage in SCI through characterizing water molecule diffusion [2-8]. The white matter of the central nervous system is highly ordered and has a coherent structure in which water diffusivity parallel to the fibers (axial diffusivity-AD) is greater than the diffusivity perpendicular to the fibers (radial diffusivity-RD). Changes in these directional diffusivities reflect white matter integrity and the underlying pathology [9-12]. Specifically, demyelination results in an increased RD, presumably due to the loss or disruption of myelin membrane integrity that hinders water diffusion perpendicular to axonal tracts $[11,13,14]$. In contrast, axonal injury leads to decreased AD levels [10,11,15].

In acute SCI, axonal loss, demyelination, edema, and cellular inflammation are all prevalent; and contribute to observed functional disability. In chronic SCI, cellular inflammation and edema are assumed to be less relevant, while axon and myelin loss are thought to be the primary substrate of functional disability. The neurological impairment of SCI patients may appear clinically similar while the underlying pathological profile may differ. Early axonal injury potentially leads to permanent disability, and may result in neurological impairment comparable with that from inflammation with minimal axonal damage, potentially reversible when inflammation or edema subsides. Early neurological impairment alone is thus not sufficient to predict the long-term outcome of a SCI patient.

While providing a valuable tool to assess white matter integrity, unfortunately it is now recognized that DTI loses specificity and sensitivity with increasing pathological and anatomical complexity $[4,16,17]$. Thus the prediction of long-term outcome using DTI remains uncertain. To overcome factors confounding DTI analysis, we have utilized diffusion basis spectrum imaging (DBSI) [4], to more accurately differentiate and quantify axonal injury, demyelination, inflammation and edema/tissue loss. While an increasing volume of work has been done utilizing DTI in traumatic brain injury, SCI, and cervical spondylotic myelopathy (CSM) it remains unclear whether brainstem and higher white matter tracts represent a useful predictor of clinical function following SCI. Furthermore, it is unclear what-if any-permanent cortical axonal loss occurs following a traumatic SCI. Recent work has demonstrated at least at the level of the spinal cord, FA values rostral to the site of injury correlate with clinical function in acute SCI [18]. We hypothesized DTI and DBSI metrics of the brainstem and internal capsule would also represent a useful predictor of clinical function in chronic SCI patients.

\section{Materials and Methods}

The Washington University Human Research Protection Office/Institutional Review Board and the Saint Louis University Institutional Review Board approved this cross-sectional study, and all subjects provided written informed consent. A prospective non-randomized cohort of 23 SCI patients and 17 control subjects underwent Magnetic Resonance Imaging (MRI) over a 12-month period. DTI and DBSI analyses were performed on whole brain diffusion weighted images. DTI and DBSI-derived indices from the internal capsule (IC) and cerebral peduncle (CP) were obtained. Clinical grading of patient functional status was made with international standards for neurological classification of spinal cord injury (ISNCSCI) [19] as modified by the American Spinal Injury Association (ASIA) Scale.

\subsection{DTI/DBSI Image Acquisition}

Magnetic resonance images were acquired using a 3 T scanner (Trio, Siemens, Erlangen, Germany) using a single-shot diffusion weighted Spin-Echo Echo Planar Imaging (SE-EPI) sequence with the following parameters: Repetition Time $(T R)=10,000 \mathrm{~ms}$; Echo Time $(\mathrm{TE})=120 \mathrm{~ms}$; Field of View $(\mathrm{FOV})=256 \times 256 \mathrm{~mm}^{2} ;$ acquisition matrix $=128 \times 128$; slice thickness $=2 \mathrm{~mm}$; in-plane resolution = 
$2 \times 2 \times 2 \mathrm{~mm}^{3}$; acquisition time $=15 \mathrm{~min}$. Diffusion weighted images were acquired in the axial plane covering the whole brain. As listed in Table A1 of Appendix A, a total 99 diffusion-encoding directions were selected as prescribed in diffusion spectrum imaging where the position vectors are the entire grid points $(q x, q y, q z)$ over the 3D q-space under the relationship that $\left(q x^{2}+q y^{2}+q z^{2}\right) \leq r^{2}(r=3$ used in current study). There were nine distinct $b$ values distributed from 0 to $2000 \mathrm{~s} / \mathrm{mm}^{2}$ on the uniformly spaced Cartesian grid (0/200/450/650/900/1100/1350/1800/2000 s/ $\left.\mathrm{mm}^{2}\right)$ [20-22]. Eddy current and motion artifacts of Diffusion Weight Image (DWI) images were corrected, then susceptibility-induced off-resonance field was estimated and corrected using TOPUP in FMRIB Software Library (FSL) [23]. Images from all subjects were registered to standard JHU-DTI-MNI single-subject atlas (also known as the "Eve Atlas" [24]). DTI and DBSI post-processing were conducted using software developed at the Mallinckrodt Institute of Radiology of Washington University in St. Louis. Standard Regions of Interest (ROIs) of CP and IC for each participant were selected based on the Johns Hopkins University (JHU) MNI template White Matter Parcellation Map (WMPM). Student's $t$-test was used for statistical analysis of group difference.

\subsection{Diffusion Basis Spectrum Imaging (DBSI)}

DBSI [4] analyzed the diffusion MRI signals as a linear combination of multiple anisotropic (representing crossing myelinated and unmyelinated axons of varied directions; the first term) and a spectrum of isotropic (resulting from cells, sub-cellular structure, and edematous water; the second term) diffusion tensors according to Equation (1):

$$
S_{k}=\sum_{i=1}^{N_{A n i s o}} f_{i} e^{-\left|\overrightarrow{b_{k}}\right| \lambda_{\perp i}} e^{-\left|\overrightarrow{b_{k}}\right|\left(\lambda_{\| i}-\lambda_{\perp i}\right) \cos ^{2} \psi_{i k}}+\int_{a}^{b} f(D) e^{-\left|\overrightarrow{b_{k}}\right| D} d D(k=1,2,3, \ldots)
$$

where $S_{k}$ and $\left|\overrightarrow{b_{k}}\right|$ are the signal and $b$-value of the $k^{\text {th }}$ diffusion gradient, $N_{\text {Aniso }}$ is the number of anisotropic tensors (fiber tracts), $\Psi_{i k}$ is the angle between the $k^{\text {th }}$ diffusion gradient and the principal direction of the $i^{\text {th }}$ anisotropic tensor, $\lambda_{\| i}$ and $\lambda_{\perp i}$ are the axial and radial diffusivities of the $i^{\text {th }}$ anisotropic tensor, $f_{i}$ is the signal intensity fraction for the $i^{\text {th }}$ anisotropic tensor, and $a$ and $b$ are the low and high diffusivity limits for the isotropic diffusion spectrum (reflecting cellularity and edema) $f(D)$ [4]. Since all pathology markers are derived using a single diffusion-weighted MRI data set in DBSI, naturally co-registered, the inherently quantitative relationship among all DBSI metrics enables the quantification of each pathological component.

\subsection{Tract-Based Spatial Statistics (TBSS)}

The whole brain voxel-wise analysis of DTI and DBSI were carried out using Tract Based Spatial Statistics (TBSS) [25], part of FSL [26]. Due to the limited number of patients, TBSS was only applied between controls and all SCI patients. First, FA images were created by fitting a tensor model to the raw diffusion data using FSL's Diffusion toolbox (FDT), and then brain-extracted using a brain extraction tool (BET) of FSL [27]. Participants' FA data were aligned into a $1 \times 1 \times 1 \mathrm{~mm}^{3}$ MNI152 space (a normalized/averaged brain developed by the Montreal Neurological Institute) by using the nonlinear registration tool FNIRT [28,29], which uses a b-spline representation of the registration warp field [30]. Next, the mean FA image was then created and thinned to create a mean FA skeleton that represents the centers of all tracts common to the group. DTI and DBSI indices were projected onto this skeleton for statistical analyses. Nonparametric permutation tests were used for voxel-wise statistical analysis of the FA skeletons between health controls and SCI patients. The significance threshold for group differences was set at $p<0.05$. Thresholding was corrected for multiple comparisons across voxels by using the threshold-free cluster-enhancement option of the tool RANDOMIZE in FSL [31]. 


\section{Results}

\subsection{Patient Characteristics}

The mean age at the time of imaging for patients was 41 years (range 15-66 and 39 for controls (range 19-68). Patient demographics are summarized in Table 1. Months since injury ranged from 1 month to 480 months. All patients with an ASIA A or B injury were at least six months out from their injury (average 103 months, range 11-480 months). We attempted to include a heterogeneous patient population reflecting various levels and severity of injury. Patients and controls were not directly age matched, but the final demographic distributions were similar in all measured parameters for all cohorts. The most common causes of injury were falls, followed by motor vehicle collisions.

\subsection{DTI Results}

As depicted in Figure 1 and Table 2, DTI indices (FA, AD, and RD) from ASIA-A/B patients are different from controls only in $\mathrm{CP}$ region. FA values were significantly lower at the level of $\mathrm{CP}$. In contrast, $\mathrm{RD}$ and $\mathrm{AD}$ values were both elevated at the level of the $\mathrm{CP}$ as compared to normal controls.

\subsection{DBSI Results}

As demonstrated in Figure 2 and Table 3, DBSI showed decreased FA values in the CP from cervical ASIA D to ASIA A/B, but not as reach significance as with DTI. AD values of ASIA A/B patients were significantly lower in $\mathrm{CP}$, while $\mathrm{RD}$ values not different, compared to controls. In contrast to DTI, edema/tissue loss can be accounted for with DBSI measures. As depicted in Figure 3, increased non-restricted fraction in the CP contributed to the elevations of both DTI AD and RD, which also explains the over-estimated DTI FA drop in CP.

\subsection{TBSS Results}

A subsequent confirmatory analysis was carried out with TBSS. Tract-based spatial statistics comparison of all SCI cohorts with healthy controls demonstrated no significant differences.
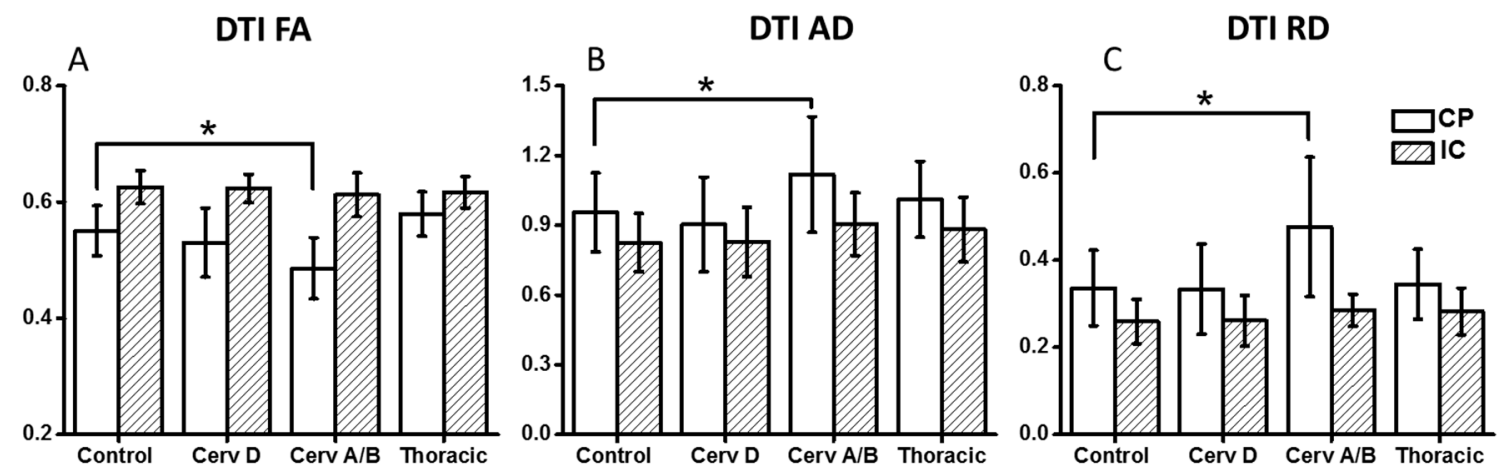

Figure 1. Compared to controls, DTI FA (A); AD (B) and RD (C) for Cervical ASIA-A/B demonstrated decreased FA and increased AD/RD in cerebral peduncle (CP) and internal capsule (IC). ${ }^{*} p<0.05$. DTI—Diffusion Tensor Imaging, FA—Fractional Anisotropy, AD—Axial Diffusivity, RD—Radial Diffusivity, ASIA-American Spinal Injury Association scale. 
Table 1. Patient Demographics.

\begin{tabular}{|c|c|c|c|c|c|c|c|c|c|c|c|}
\hline ID & Age & Race & Sex & Age at Injury & $\begin{array}{l}\text { Months Since } \\
\text { Injury }\end{array}$ & $\begin{array}{l}\text { Mechanism of } \\
\text { Injury }\end{array}$ & Severity & $\begin{array}{l}\text { Initial } \\
\text { ASIA }\end{array}$ & $\begin{array}{c}\text { Initial Site } \\
\text { of Injury }\end{array}$ & $\begin{array}{c}\text { Isncsci Motor } \\
\text { Max } 100\end{array}$ & $\begin{array}{c}\text { Isncsci Sensory } \\
\text { Max } 224\end{array}$ \\
\hline 1 & 46 & AA & M & 46 & 1 & Fall & Incomplete & $\mathrm{D}$ & $\mathrm{C} 5$ & 96 & 224 \\
\hline 2 & 15 & $\mathrm{AA}$ & $\mathrm{M}$ & 15 & 1 & Fall & Incomplete & $\mathrm{D}$ & C6 & 90 & 224 \\
\hline 3 & 41 & $\mathrm{AA}$ & M & 32 & 107 & MVC & Complete & $\mathrm{A}$ & $\mathrm{C} 4$ & 5 & 28 \\
\hline 4 & 45 & $\mathrm{C}$ & $\mathrm{F}$ & 44 & 16 & MVC & Complete & A & T9 & 50 & 120 \\
\hline 5 & 27 & C & $\mathrm{F}$ & 25 & 18 & Fall & Incomplete & $\mathrm{D}$ & C6 & 77 & 219 \\
\hline 6 & 40 & $\mathrm{C}$ & $\mathrm{M}$ & 21 & 233 & Baseball & Complete & $\mathrm{A}$ & $\mathrm{C} 4$ & 10 & 32 \\
\hline 7 & 66 & AA & $\mathrm{F}$ & 65 & 13 & MVC & Complete & A & C6 & 30 & 88 \\
\hline 8 & 54 & $\mathrm{C}$ & $\mathrm{F}$ & 50 & 40 & Fall & Incomplete & $\mathrm{D}$ & C6 & 42 & 216 \\
\hline 9 & 26 & C & M & 26 & 11 & MVC & Complete & A & $\mathrm{T} 5$ & 50 & 84 \\
\hline 10 & 56 & $\mathrm{C}$ & M & 56 & 2 & Fall & Incomplete & $\mathrm{D}$ & C6 & 95 & 216 \\
\hline 11 & 32 & C & M & 20 & 145 & MVC & Incomplete & C & $\mathrm{T} 4$ & 90 & 156 \\
\hline 12 & 48 & $\mathrm{C}$ & M & 47 & 16 & MVC & Complete & $\mathrm{A}$ & C6 & 10 & 88 \\
\hline 13 & 50 & $\mathrm{AA}$ & M & 50 & 3 & Fall & Incomplete & $\mathrm{D}$ & $\mathrm{C} 4$ & 98 & 220 \\
\hline 14 & 19 & C & $\mathrm{F}$ & 16 & 30 & MVC & Incomplete & $\mathrm{D}$ & $\mathrm{T} 12$ & 70 & 184 \\
\hline 15 & 36 & $\mathrm{C}$ & $\mathrm{M}$ & 35 & 19 & Fall & Complete & $\mathrm{A}$ & $\mathrm{T} 11$ & 50 & 138 \\
\hline 16 & 59 & AA & $\mathrm{M}$ & 59 & 1 & Fall & Incomplete & $\mathrm{D}$ & $\mathrm{C} 5$ & 98 & 224 \\
\hline 17 & 24 & $\mathrm{C}$ & $\mathrm{M}$ & 20 & 45 & MVC & Complete & A & T9 & 50 & 176 \\
\hline 18 & 68 & C & M & 28 & 480 & MVC & Incomplete & B & $\mathrm{C} 8$ & 46 & 156 \\
\hline 19 & 57 & C & M & 57 & 1 & $\begin{array}{l}\text { Hit by } 500 l b \\
\text { sign }\end{array}$ & Incomplete & $\mathrm{D}$ & $\mathrm{T} 7 / \mathrm{T} 8$ & 92 & 208 \\
\hline 20 & 53 & C & M & 52 & 3 & Fall & Incomplete & $\mathrm{D}$ & $\mathrm{C} 4$ & 82 & 132 \\
\hline 21 & 56 & $\mathrm{C}$ & M & 52 & 55 & MVC & Complete & A & $\mathrm{C} 7$ & 20 & 16 \\
\hline 22 & 36 & C & M & 36 & 3 & Motorcycle & Complete & A & L1 & 53 & 160 \\
\hline 23 & 71 & $\mathrm{C}$ & M & 71 & 2 & Fall & Incomplete & $\mathrm{D}$ & C4/C5 & 90 & 212 \\
\hline
\end{tabular}

ASIA—American Spinal Injury Association Scale, C—Caucasian, AA—African American, M-Male, F-Female, MVC—motor vehicle collision. 
Table 2. DTI Results-Brainstem and internal capsule.

\begin{tabular}{cccccc}
\hline Region & Group & FA & ADC & AD & RD \\
\hline & Control & $0.55 \pm 0.04$ & $0.54 \pm 0.11$ & $0.96 \pm 0.17$ & $0.34 \pm 0.09$ \\
& Cervical D & $0.53 \pm 0.06$ & $0.52 \pm 0.13$ & $0.90 \pm 0.20$ & $0.33 \pm 0.10$ \\
Cerebral & Cervical A/B & $0.48 \pm 0.06$ & $0.69 \pm 0.19$ & $1.12 \pm 0.25$ & $0.48 \pm 0.16$ \\
peduncle (CP) & Thoracic A/B/C/D & $0.57 \pm 0.04$ & $0.56 \pm 0.11$ & $1.01 \pm 0.16$ & $0.34 \pm 0.08$ \\
\hline & Control & $0.63 \pm 0.03$ & $0.45 \pm 0.07$ & $0.83 \pm 0.13$ & $0.26 \pm 0.05$ \\
& Cervical D & $0.62 \pm 0.02$ & $0.46 \pm 0.08$ & $0.83 \pm 0.15$ & $0.26 \pm 0.06$ \\
Internal & Cervical A/B & $0.61 \pm 0.04$ & $0.53 \pm 0.06$ & $0.90 \pm 0.14$ & $0.28 \pm 0.04$ \\
capsule (IC) & Thoracic A/B/C/D & $0.62 \pm 0.03$ & $0.48 \pm 0.08$ & $0.88 \pm 0.14$ & $0.28 \pm 0.05$ \\
\hline
\end{tabular}

DTI—Diffusion Tensor Imaging, FA—Fractional Anisotropy, ADC—Apparent Diffusion Coefficient, AD—Axial Diffusivity, RD—Radial Diffusivity, ASIA—American Spinal Injury Association scale.

DBSI FA

A

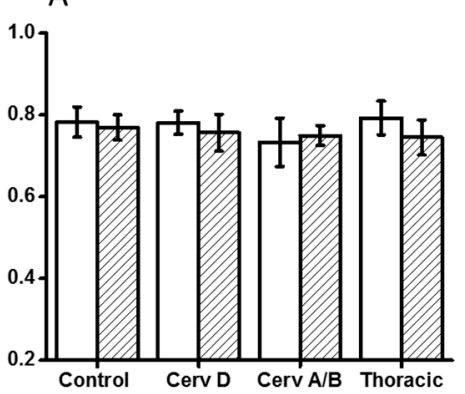

DBSI Fiber AD

B

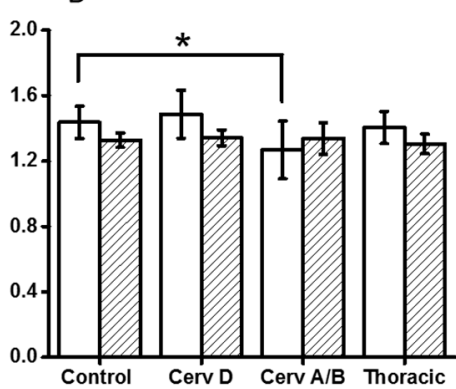

DBSI Fiber RD

C

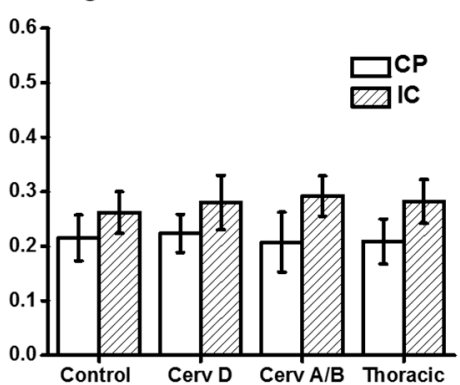

Figure 2. DBSI FA (A) and DBSI AD (B) and RD (C) values of Control, Cervical ASIA-A/B, Thoracic ASIA-A/B/C/D patients. Cervical ASIA-A/B patients had significantly lower DBSI AD values compared to controls and Cervical ASIA-D patients at the level of the cerebral peduncle. This difference was not observed higher up in the internal capsule. ${ }^{*} p<0.05$. DBSI—Diffusion Basis Spectrum Imaging, FA—Fractional Anisotropy, AD—Axial Diffusivity, RD—Radial Diffusivity, ASIA—American Spinal Injury Association scale.

\section{DBSI non-restricted}

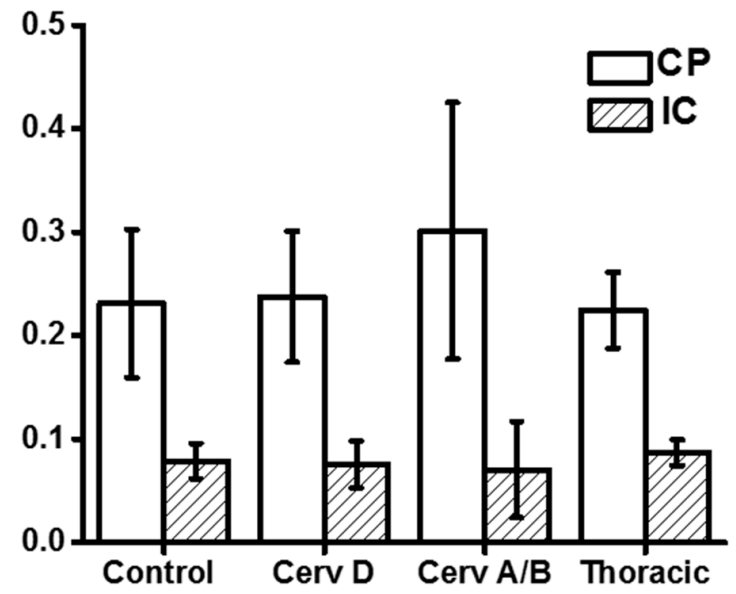

Figure 3. Compared to controls, DBSI derived non-restricted fraction at the level of the cerebral peduncle and internal capsule increase for cervical ASIA-A/B patients. DBSI-Diffusion Basis Spectrum Imaging, FA-Fractional Anisotropy, ADC—Apparent Diffusion Coefficient, AD—Axial Diffusivity, RD—Radial Diffusivity, ASIA-American Spinal Injury Association scale, CP-Cerebral Peduncle, IC-Internal Capsule. 
Table 3. DBSI Results-Brainstem and internal capsule.

\begin{tabular}{|c|c|c|c|c|c|c|}
\hline Region & Group & $\begin{array}{l}\text { Fiber } \\
\text { Fraction }\end{array}$ & Fiber FA & Fiber AD & Fiber RD & $\begin{array}{l}\text { Non-Restricted } \\
\text { Fraction }\end{array}$ \\
\hline \multirow{4}{*}{$\begin{array}{l}\text { Cerebral } \\
\text { peduncle }\end{array}$} & Control & $0.53 \pm 0.07$ & $0.78 \pm 0.04$ & $1.44 \pm 0.10$ & $0.22 \pm 0.04$ & $0.23 \pm 0.07$ \\
\hline & Cervical D & $0.49 \pm 0.06$ & $0.78 \pm 0.03$ & $1.49 \pm 0.15$ & $0.22 \pm 0.04$ & $0.24 \pm 0.06$ \\
\hline & Cervical A/B & $0.50 \pm 0.10$ & $0.73 \pm 0.06$ & $1.27 \pm 0.18$ & $0.21 \pm 0.05$ & $0.30 \pm 0.12$ \\
\hline & Thoracic A/B/C/D & $0.57 \pm 0.07$ & $0.79 \pm 0.04$ & $1.40 \pm 0.10$ & $0.21 \pm 0.04$ & $0.22 \pm 0.04$ \\
\hline \multirow{4}{*}{$\begin{array}{l}\text { Internal } \\
\text { capsule }\end{array}$} & Control & $0.74 \pm 0.07$ & $0.77 \pm 0.03$ & $1.33 \pm 0.04$ & $0.26 \pm 0.04$ & $0.08 \pm 0.02$ \\
\hline & Cervical D & $0.72 \pm 0.08$ & $0.76 \pm 0.05$ & $1.34 \pm 0.05$ & $0.28 \pm 0.05$ & $0.08 \pm 0.02$ \\
\hline & Cervical A/B & $0.77 \pm 0.06$ & $0.75 \pm 0.02$ & $1.34 \pm 0.10$ & $0.29 \pm 0.04$ & $0.07 \pm 0.05$ \\
\hline & Thoracic A/B/C/D & $0.74 \pm 0.07$ & $0.75 \pm 0.04$ & $1.31 \pm 0.06$ & $0.28 \pm 0.04$ & $0.09 \pm 0.01$ \\
\hline
\end{tabular}

\section{Discussion}

While conventional MRI provides details about the degree of spinal cord compression, parenchymal edema, and evidence of hemorrhage after an acute SCI, it provides no information about preserved axonal integrity $[32,33]$. Increasingly, DTI has been proposed as a surrogate marker for injury in both CSM and SCI [18,34-37]. In chronic disease, we would expect axonal loss at the zone of injury but what has remained unclear is whether Wallerian degeneration extends rostrally above the cortical spinal tracts and into the brain. Previous work with DTI has shown that DTI metrics are confounded by increased cellularity and vasogenic edema in ongoing states of acute or ongoing compression such as CSM or acute SCI. DBSI has been proposed to address DTI limitations by resolving multiple-tensor water diffusion resulting from axon injury, demyelination, and inflammation [4]. In a chronic disease state, we hypothesized both DTI and DBSI would demonstrate axonal loss extending to the level of the $\mathrm{CP}$ and IC, resulting in decreased FA and AD values that correlate with disease severity. DTI identified changes of $\mathrm{FA}, \mathrm{AD}$, and $\mathrm{RD}$ for ASIA-A/B patients at the level of $\mathrm{CP}$. However as increasingly reported in the literature, interpretations of DTI indices are not specific as pathologic complexity increases. DBSI results suggested axonal injury and edema/tissue loss in CP for ASIA-A/B patients that increased with injury severity. Indeed, Cervical ASIA A/B SCI patients had higher levels of axonal injury and edema/tissue loss as measured by DBSI at the level of the cerebral peduncle. DTI was able to detect differences in cervical ASIA A/B patients (FA, AD, and RD), but they were non-specific to pathologies. Increased water fraction indicated by DBSI non-restricted isotropic diffusion fraction in the cerebral peduncle explains the simultaneously increased DTI AD and DTI RD values. Our results further demonstrate the utility of DTI to detect disruption in axonal integrity in white matter, yet a clear shortcoming in differentiating true axonal injury from inflammation/tissue loss.

The whole-brain analysis using TBSS failed to detect any statistical difference on all DTI and DBSI indices. While this automated whole-brain analysis can reveal locations of effects globally, minor changes may be harder to detect by TBSS because voxels more distant from tract centers contribute less to the average value projected on the skeleton [38].

Although SCI does not result in injury to cortical neurons, it does produce a physiologic disconnection of the distal motor targets, and it disassociates the sensorimotor areas. The cortical reorganization that occurs after SCI is not well defined. Previous authors have suggested there is loss of grey and white matter volume in cervical SCI patients as compared to normal controls [39]. Using functional MRI (fMRI) and positron emission tomography (PET) imaging, multiple authors have also reported increased cortical and subcortical activation in patients with SCI [40-43]. By contrast, several authors have reported no change or decreased cortical activation in individuals with SCI [44-47]. The significance of fMRI and PET studies remains unclear and provides no direct information regarding preserved axonal integrity. What does seem abundantly clear is that cortical reorganization occurs following SCI, but how this affects one's potential for subsequent functional recovery or response to adjunctive treatment remains unclear [48-50]. 
Recently, Kurpad SN et al. [50] described changes that occur in network connectivity following $\mathrm{SCI}$ using resting state fMRI. The authors reported reduced functional connectivity in the sensorimotor cortex from SCI patients as compared to normal controls, yet an increase in connectivity with the thalamus. These dynamic changes seem intuitive given the known mismatch in efferent and afferent axons that occurs after SCI and further supports previous fMRI and PET studies that neural plasticity does allow for a shift in cortical connectivity, but what still remains unclear is whether this leads to subsequent axonal loss.

Only recently has DTI been used to investigate the cortical and subcortical changes that are thought to occur after SCI. In patients with chronic SCIs (i.e., >24 months), several authors have reported DTI metrics of brain CSTs decrease as compared with normal controls [51,52]. While we did find increased RD, and decreased FA and AD at the level of the CPs, this difference resolved rostrally at the level of the IC. However the AD, a marker for axonal injury, is supposed to decrease, not increase. Due to the limitation of single tensor model of DTI, both AD and RD will be elevated when edema/tissue loss is present. In such case, DTI overestimates axonal injury and demyelination. This loss would be expected with Wallerian degeneration occurring above the level of SCI. What is not well-defined is how much degeneration occurs at the level of internal capsule and cortically. DBSI was developed to address multiple co-existing pathologies by modeling anisotropic diffusion components (fiber tracts) from isotropic ones (structures and pathologies surrounding fiber tracts). Thus, DBSI can quantitatively evaluate fiber integrity, as well as edema/tissue loss and inflammation.

In the current study, DBSI results demonstrated both axonal injury and edema/tissue loss occurred at the level of CP in cervical ASIA-A/B patient, but not in any other patients as compared to normal controls. Furthermore, no differences were observed in any of the groups for any of the metrics at the level of the internal capsule. While cortical reorganization has been described following traumatic SCI [50,53-55], our results may help explain why patients, even years after a complete SCI, respond to epidural stimulation [56-59] and why recovery was observed following nerve transfers for SCI [60,61]. The loss of somatosensory input may redirect cortical activity, but as suggested by our results, does not necessarily lead to axonal loss. These results are promising and have implications for future trials aimed at treating chronic SCI.

Limitations-There are several limitations to consider from the presented data. First is the low numbers of patients, which may potentially account for the lack of any significant differences across the SCI cohorts. Second is lack of additional connectivity data, ideally this data could be corrected with resting state fMRI to assess concurrent changes in the various states of SCI.

\section{Conclusions}

MRI and increasingly advanced sequences such as DTI and DBSI provide guidance in the management and diagnosis of CNS pathologies. DTI and DBSI have been proposed as non-invasive tools that measure both axonal injury and demyelination. In this small subset of patients, DTI and DBSI measures of axonal loss and demyelination did not correlate with patient functional status. These results are promising to future regenerative treatment strategies, demonstrating axons may be preserved rostrally at the site of injury. This preservation at a higher cortical level may provide some insight as to why some patients respond to more recent epidural stimulation even years out from injury.

Acknowledgments: This study was supported by University of Missouri Spinal Cord Injury Research Program (Wilson Z. Ray) and National Institute of Health K23NS084932 (Wilson Z. Ray).

Author Contributions: Wilson Z. Ray, Rory K.J. Murphy, Peng Sun, and Sheng-Kwei Song conceived and designed the study. Sheng-Kwei Song and Peng Sun analyzed the data. Wilson Z. Ray, Rory K.J. Murphy, Peng Sun, and Sheng-Kwei Song wrote the paper. Paul Gamble and Ajit George assisted in data collection, preparation of manuscript, and review of the manuscript.

Conflicts of Interest: Wilson Z. Ray has the following conflicts of interest to report: Depuy, Ulrich, Globus Consulting, Department of Defense Grant, and NIH grant support. Sheng-Kwei Song has the following conflicts of interest to report: NIH grant support. All other authors have no conflict of interest to report. 
The founding sponsors had no role in the design of the study; in the collection, analyses, or interpretation of data; in the writing of the manuscript, and in the decision to publish the results.

\section{Appendix A}

Table A1. Diffusion vector table.

\begin{tabular}{|c|c|c|c|}
\hline & $x$ & $y$ & $z$ \\
\hline 1 & -1.0000 & 0.0000 & 0.0000 \\
\hline 2 & -0.6667 & -0.6667 & 0.0000 \\
\hline 3 & -0.6667 & -0.3333 & -0.3333 \\
\hline 4 & -0.6667 & -0.3333 & 0.0000 \\
\hline 5 & -0.6667 & -0.3333 & 0.3333 \\
\hline 6 & -0.6667 & 0.0000 & -0.6667 \\
\hline 7 & -0.6667 & 0.0000 & -0.3333 \\
\hline 8 & -0.6667 & 0.0000 & 0.0000 \\
\hline 9 & -0.6667 & 0.0000 & 0.3333 \\
\hline 10 & -0.6667 & 0.0000 & 0.6667 \\
\hline 11 & -0.6667 & 0.3333 & -0.3333 \\
\hline 12 & -0.6667 & 0.3333 & 0.0000 \\
\hline 13 & -0.6667 & 0.3333 & 0.3333 \\
\hline 14 & -0.6667 & 0.6667 & 0.0000 \\
\hline 15 & -0.3333 & -0.6667 & -0.3333 \\
\hline 16 & -0.3333 & -0.6667 & 0.0000 \\
\hline 17 & -0.3333 & -0.6667 & 0.3333 \\
\hline 18 & -0.3333 & -0.3333 & -0.6667 \\
\hline 19 & -0.3333 & -0.3333 & -0.3333 \\
\hline 20 & -0.3333 & -0.3333 & 0.0000 \\
\hline 21 & -0.3333 & -0.3333 & 0.3333 \\
\hline 22 & -0.3333 & -0.3333 & 0.6667 \\
\hline 23 & -0.3333 & 0.0000 & -0.6667 \\
\hline 24 & -0.3333 & 0.0000 & -0.3333 \\
\hline 25 & -0.3333 & 0.0000 & 0.0000 \\
\hline 26 & -0.3333 & 0.0000 & 0.3333 \\
\hline 27 & -0.3333 & 0.0000 & 0.6667 \\
\hline 28 & -0.3333 & 0.3333 & -0.6667 \\
\hline 29 & -0.3333 & 0.3333 & -0.3333 \\
\hline 30 & -0.3333 & 0.3333 & 0.0000 \\
\hline 31 & -0.3333 & 0.3333 & 0.3333 \\
\hline 32 & -0.3333 & 0.3333 & 0.6667 \\
\hline 33 & -0.3333 & 0.6667 & -0.3333 \\
\hline 34 & -0.3333 & 0.6667 & 0.0000 \\
\hline 35 & -0.3333 & 0.6667 & 0.3333 \\
\hline 36 & 0.0000 & -1.0000 & 0.0000 \\
\hline 37 & 0.0000 & -0.6667 & -0.6667 \\
\hline 38 & 0.0000 & -0.6667 & -0.3333 \\
\hline 39 & 0.0000 & -0.6667 & 0.0000 \\
\hline 40 & 0.0000 & -0.6667 & 0.3333 \\
\hline 41 & 0.0000 & -0.6667 & 0.6667 \\
\hline 42 & 0.0000 & -0.3333 & -0.6667 \\
\hline 43 & 0.0000 & -0.3333 & -0.3333 \\
\hline 44 & 0.0000 & -0.3333 & 0.0000 \\
\hline 45 & 0.0000 & -0.3333 & 0.3333 \\
\hline 46 & 0.0000 & -0.3333 & 0.6667 \\
\hline 47 & 0.0000 & 0.0000 & -1.0000 \\
\hline 48 & 0.0000 & 0.0000 & -0.6667 \\
\hline 49 & 0.0000 & 0.0000 & -0.3333 \\
\hline 50 & 0.0000 & 0.0000 & 0.0000 \\
\hline 51 & 0.0000 & 0.0000 & 0.3333 \\
\hline
\end{tabular}


Table A1. Cont.

\begin{tabular}{|c|c|c|c|}
\hline & $x$ & $y$ & $z$ \\
\hline 52 & 0.0000 & 0.0000 & 0.6667 \\
\hline 53 & 0.0000 & 0.0000 & 1.0000 \\
\hline 54 & 0.0000 & 0.3333 & -0.6667 \\
\hline 55 & 0.0000 & 0.3333 & -0.3333 \\
\hline 56 & 0.0000 & 0.3333 & 0.0000 \\
\hline 57 & 0.0000 & 0.3333 & 0.3333 \\
\hline 58 & 0.0000 & 0.3333 & 0.6667 \\
\hline 59 & 0.0000 & 0.6667 & -0.6667 \\
\hline 60 & 0.0000 & 0.6667 & -0.3333 \\
\hline 61 & 0.0000 & 0.6667 & 0.0000 \\
\hline 62 & 0.0000 & 0.6667 & 0.3333 \\
\hline 63 & 0.0000 & 0.6667 & 0.6667 \\
\hline 64 & 0.0000 & 1.0000 & 0.0000 \\
\hline 65 & 0.3333 & -0.6667 & -0.3333 \\
\hline 66 & 0.3333 & -0.6667 & 0.0000 \\
\hline 67 & 0.3333 & -0.6667 & 0.3333 \\
\hline 68 & 0.3333 & -0.3333 & -0.6667 \\
\hline 69 & 0.3333 & -0.3333 & -0.3333 \\
\hline 70 & 0.3333 & -0.3333 & 0.0000 \\
\hline 71 & 0.3333 & -0.3333 & 0.3333 \\
\hline 72 & 0.3333 & -0.3333 & 0.6667 \\
\hline 73 & 0.3333 & 0.0000 & -0.6667 \\
\hline 74 & 0.3333 & 0.0000 & -0.3333 \\
\hline 75 & 0.3333 & 0.0000 & 0.0000 \\
\hline 76 & 0.3333 & 0.0000 & 0.3333 \\
\hline 77 & 0.3333 & 0.0000 & 0.6667 \\
\hline 78 & 0.3333 & 0.3333 & -0.6667 \\
\hline 79 & 0.3333 & 0.3333 & -0.3333 \\
\hline 80 & 0.3333 & 0.3333 & 0.0000 \\
\hline 81 & 0.3333 & 0.3333 & 0.3333 \\
\hline 82 & 0.3333 & 0.3333 & 0.6667 \\
\hline 83 & 0.3333 & 0.6667 & -0.3333 \\
\hline 84 & 0.3333 & 0.6667 & 0.0000 \\
\hline 85 & 0.3333 & 0.6667 & 0.3333 \\
\hline 86 & 0.6667 & -0.6667 & 0.0000 \\
\hline 87 & 0.6667 & -0.3333 & -0.3333 \\
\hline 88 & 0.6667 & -0.3333 & 0.0000 \\
\hline 89 & 0.6667 & -0.3333 & 0.3333 \\
\hline 90 & 0.6667 & 0.0000 & -0.6667 \\
\hline 91 & 0.6667 & 0.0000 & -0.3333 \\
\hline 92 & 0.6667 & 0.0000 & 0.0000 \\
\hline 93 & 0.6667 & 0.0000 & 0.3333 \\
\hline 94 & 0.6667 & 0.0000 & 0.6667 \\
\hline 95 & 0.6667 & 0.3333 & -0.3333 \\
\hline 96 & 0.6667 & 0.3333 & 0.0000 \\
\hline 97 & 0.6667 & 0.3333 & 0.3333 \\
\hline 98 & 0.6667 & 0.6667 & 0.0000 \\
\hline 99 & 1.0000 & 0.0000 & 0.0000 \\
\hline
\end{tabular}

\section{References}

1. Ackery, A.; Tator, C.; Krassioukov, A. A global perspective on spinal cord injury epidemiology. J Neurotraum. 2004, 21, 1355-1370. [CrossRef]

2. Kim, J.H.; Loy, D.N.; Liang, H.F.; Trinkaus, K.; Schmidt, R.E.; Song, S.K. Noninvasive diffusion tensor imaging of evolving white matter pathology in a mouse model of acute spinal cord injury. Magn. Reson. Med. 2007, 58, 253-260. [CrossRef] [PubMed] 
3. Naismith, R.T.; Xu, J.; Klawiter, E.C.; Lancia, S.; Tutlam, N.T.; Wagner, J.M.; Qian, P.; Trinkaus, K.; Song, S.K.; Cross, A.H. Spinal cord tract diffusion tensor imaging reveals disability substrate in demyelinating disease. Neurology 2013, 80, 2201-2209. [CrossRef] [PubMed]

4. Wang, Y.; Wang, Q.; Haldar, J.P.; Yeh, F.C.; Xie, M.; Sun, P.; Tu, T.W.; Trinkaus, K.; Klein, R.S.; Cross, A.H.; et al. Quantification of increased cellularity during inflammatory demyelination. Brain 2011, 134 Pt 12, 3590-3601. [CrossRef] [PubMed]

5. Barker, G.J. Diffusion-weighted imaging of the spinal cord and optic nerve. J. Neurol. Sci. 2001, 186 (Suppl. 1), S45-S49. [CrossRef]

6. Sotak, C.H. The role of diffusion tensor imaging in the evaluation of ischemic brain injury-A review. NMR Biomed. 2002, 15, 561-569. [CrossRef] [PubMed]

7. Le Bihan, D.; Mangin, J.F.; Poupon, C.; Clark, C.A.; Pappata, S.; Molko, N.; Chabriat, H. Diffusion tensor imaging: Concepts and applications. J. Magn. Reson. Imag. 2001, 13, 534-546. [CrossRef] [PubMed]

8. Mori, S.; van Zijl, P.C. Fiber tracking: Principles and strategies-A technical review. NMR Biomed. 2002, 15, 468-480. [CrossRef] [PubMed]

9. Deo, A.A.; Grill, R.J.; Hasan, K.M.; Narayana, P.A. In vivo serial diffusion tensor imaging of experimental spinal cord injury. J. Neurosci. Res. 2006, 83, 801-810. [CrossRef] [PubMed]

10. Kim, J.H.; Budde, M.D.; Liang, H.F.; Klein, R.S.; Russell, J.H.; Cross, A.H.; Song, S.K. Detecting axon damage in spinal cord from a mouse model of multiple sclerosis. Neurobiol. Dis. 2006, 21, 626-632. [CrossRef] [PubMed]

11. Song, S.K.; Sun, S.W.; Ju, W.K.; Lin, S.J.; Cross, A.H.; Neufeld, A.H. Diffusion tensor imaging detects and differentiates axon and myelin degeneration in mouse optic nerve after retinal ischemia. Neuroimage 2003, 20, 1714-1722. [CrossRef] [PubMed]

12. Song, S.K.; Sun, S.W.; Ramsbottom, M.J.; Chang, C.; Russell, J.; Cross, A.H. Dysmyelination revealed through MRI as increased radial (but unchanged axial) diffusion of water. Neuroimage 2002, 17, 1429-1436. [CrossRef] [PubMed]

13. Song, S.K.; Yoshino, J.; Le, T.Q.; Lin, S.J.; Sun, S.W.; Cross, A.H.; Armstrong, R.C. Demyelination increases radial diffusivity in corpus callosum of mouse brain. Neuroimage 2005, 26, 132-140. [CrossRef] [PubMed]

14. Sun, S.W.; Liang, H.F.; Trinkaus, K.; Cross, A.H.; Armstrong, R.C.; Song, S.K. Noninvasive detection of cuprizone induced axonal damage and demyelination in the mouse corpus callosum. Magn. Reson. Med. 2006, 55, 302-308. [CrossRef] [PubMed]

15. Budde, M.D.; Kim, J.H.; Liang, H.F.; Schmidt, R.E.; Russell, J.H.; Cross, A.H.; Song, S.K. Toward accurate diagnosis of white matter pathology using diffusion tensor imaging. Magn. Reson. Med. 2007, 57, 688-695. [CrossRef] [PubMed]

16. Chiang, C.W.; Wang, Y.; Sun, P.; Lin, T.H.; Trinkaus, K.; Cross, A.H.; Song, S.K. Quantifying white matter tract diffusion parameters in the presence of increased extra-fiber cellularity and vasogenic edema. Neuroimage 2014, 101, 310-319. [CrossRef] [PubMed]

17. Wang, X.; Cusick, M.F.; Wang, Y.; Sun, P.; Libbey, J.E.; Trinkaus, K.; Fujinami, R.S.; Song, S.K. Diffusion basis spectrum imaging detects and distinguishes coexisting subclinical inflammation, demyelination and axonal injury in experimental autoimmune encephalomyelitis mice. NMR Biomed. 2014, 27, 843-852. [CrossRef] [PubMed]

18. Vedantam, A.; Jirjis, M.B.; Schmit, B.D.; Wang, M.C.; Ulmer, J.L.; Kurpad, S.N. Diffusion tensor imaging of the spinal cord: Insights from animal and human studies. Neurosurgery 2014, 74, 1-8. [CrossRef] [PubMed]

19. Kirshblum, S.; Waring, W., 3rd. Updates for the International Standards for Neurological Classification of Spinal Cord Injury. Phys. Med. Rehabil. Clin. N. Am. 2014, 25, 505-517. [CrossRef] [PubMed]

20. Wedeen, V.J.; Hagmann, P.; Tseng, W.Y.I.; Reese, T.G.; Weisskoff, R.M. Mapping complex tissue architecture with diffusion spectrum magnetic resonance imaging. Magn. Reson. Med. 2005, 54, 1377-1386. [CrossRef] [PubMed]

21. Kuo, L.W.; Chen, J.H.; Wedeen, V.J.; Tseng, W.Y.I. Optimization of diffusion spectrum imaging and q-ball imaging on clinical MRI system. NeuroImage 2008, 41, 7-18. [CrossRef] [PubMed]

22. Wang, Y.; Sun, P.; Wang, Q.; Trinkaus, K.; Schmidt, R.E.; Naismith, R.T.; Cross, A.H.; Song, S.K. Differentiation and quantification of inflammation, demyelination and axon injury or loss in multiple sclerosis. Brain 2015, 138, 1223-1238. [CrossRef] [PubMed]

23. Andersson, J.L.; Skare, S.; Ashburner, J. How to correct susceptibility distortions in spin-echo echo-planar images: Application to diffusion tensor imaging. Neuroimage 2003, 20, 870-888. [CrossRef] 
24. Oishi, K.; Zilles, K.; Amunts, K.; Faria, A.; Jiang, H.; Li, X.; Akhter, K.; Hua, K.; Woods, R.; Toga, A.W.; et al. Human brain white matter atlas: Identification and assignment of common anatomical structures in superficial white matter. Neuroimage 2008, 43, 447-457. [CrossRef] [PubMed]

25. Smith, S.M.; Jenkinson, M.; Johansen-Berg, H.; Rueckert, D.; Nichols, T.E.; Mackay, C.E.; Watkins, K.E.; Ciccarelli, O.; Cader, M.Z.; Matthews, P.M.; et al. Tract-based spatial statistics: Voxelwise analysis of multi-subject diffusion data. Neuroimage 2006, 31, 1487-1505. [CrossRef] [PubMed]

26. Smith, S.M.; Jenkinson, M.; Woolrich, M.W.; Beckmann, C.F.; Behrens, T.E.; Johansen-Berg, H.; Bannister, P.R.; De Luca, M.; Drobnjak, I.; Flitney, D.E.; et al. Advances in functional and structural MR image analysis and implementation as FSL. Neuroimage 2004, 23, S208-S219. [CrossRef] [PubMed]

27. Smith, S.M. Fast robust automated brain extraction. Hum. Brain Mapp. 2002, 17, 143-155. [CrossRef] [PubMed]

28. Andersson, J.L.R.; Jenkinson, M.; Smith, S. Non-Linear Optimisation. FMRIB Technical Report TR07JA1. Available online: http://www.fmrib.ox.ac.uk/datasets/techrep/tr07ja1/tr07ja1.pdf (accessed on 16 February 2017).

29. Andersson, J.L.R.; Jenkinson, M.; Smith, S. Non-Linear Registration, aka Spatial Normalisation FMRIB Technical Report TR07JA2. Available online: http://www.fmrib.ox.ac.uk/datasets/techrep/tr07ja2/tr07ja2. pdf (accessed on 16 February 2017).

30. Rueckert, D.; Sonoda, L.I.; Hayes, C.; Hill, D.L.; Leach, M.O.; Hawkes, D.J. Nonrigid registration using free-form deformations: Application to breast MR images. IEEE Trans. Med. Imag. 1999, 18, 712-721. [CrossRef] [PubMed]

31. Winkler, A.M.; Ridgway, G.R.; Webster, M.A.; Smith, S.M.; Nichols, T.E. Permutation inference for the general linear model. Neuroimage 2014, 92, 381-397. [CrossRef] [PubMed]

32. Miyanji, F.; Furlan, J.C.; Aarabi, B.; Arnold, P.M.; Fehlings, M.G. Acute cervical traumatic spinal cord injury: MR imaging findings correlated with neurologic outcome-Prospective study with 100 consecutive patients. Radiology 2007, 243, 820-827. [CrossRef] [PubMed]

33. Shepard, M.J.; Bracken, M.B. Magnetic resonance imaging and neurological recovery in acute spinal cord injury: Observations from the National Acute Spinal Cord Injury Study 3. Spinal Cord 1999, 37, 833-837. [CrossRef] [PubMed]

34. Li, X.; Cui, J.L.; Mak, K.C.; Luk, K.D.; Hu, Y. Potential use of diffusion tensor imaging in level diagnosis of multilevel cervical spondylotic myelopathy. Spine 2014, 39, E615-E622. [CrossRef] [PubMed]

35. Gao, S.J.; Yuan, X.; Jiang, X.Y.; Liu, X.X.; Liu, X.P.; Wang, Y.F.; Cao, J.B.; Bai, L.N.; Xu, K. Correlation study of 3T-MR-DTI measurements and clinical symptoms of cervical spondylotic myelopathy. Eur. J. Radiol. 2013, 82, 1940-1945. [CrossRef] [PubMed]

36. Koskinen, E.; Brander, A.; Hakulinen, U.; Luoto, T.; Helminen, M.; Ylinen, A.; Ohman, J. Assessing the state of chronic spinal cord injury using diffusion tensor imaging. J. Neurotrauma 2013, 30, 1587-1595. [CrossRef] [PubMed]

37. Vedantam, A.; Eckardt, G.; Wang, M.C.; Schmit, B.D.; Kurpad, S.N. Clinical Correlates of High Cervical Fractional Anisotropy in Acute Cervical Spinal Cord Injury. World Neurosurg. 2015, 83, 824-828. [CrossRef] [PubMed]

38. Zalesky, A. Moderating registration misalignment in voxelwise comparisons of DTI data: A performance evaluation of skeleton projection. Magn. Reson. Imag. 2011, 29, 111-125. [CrossRef] [PubMed]

39. Freund, P.; Weiskopf, N.; Ward, N.S.; Hutton, C.; Gall, A.; Ciccarelli, O.; Craggs, M.; Friston, K.; Thompson, A.J. Disability, atrophy and cortical reorganization following spinal cord injury. Brain 2011, 134 Pt 6, 1610-1622. [CrossRef] [PubMed]

40. Alkadhi, H.; Brugger, P.; Boendermaker, S.H.; Crelier, G.; Curt, A.; Hepp-Reymond, M.C.; Kollias, S.S. What disconnection tells about motor imagery: Evidence from paraplegic patients. Cereb. Cortex 2005, 15, 131-140. [CrossRef] [PubMed]

41. Bruehlmeier, M.; Dietz, V.; Leenders, K.L.; Roelcke, U.; Missimer, J.; Curt, A. How does the human brain deal with a spinal cord injury? Eur. J. Neurosci. 1998, 10, 3918-3922. [CrossRef] [PubMed]

42. Cramer, S.C.; Lastra, L.; Lacourse, M.G.; Cohen, M.J. Brain motor system function after chronic, complete spinal cord injury. Brain 2005, 128 Pt 12, 2941-2950. [CrossRef] [PubMed]

43. Hotz-Boendermaker, S.; Funk, M.; Summers, P.; Brugger, P.; Hepp-Reymond, M.C.; Curt, A.; Kollias, S.S. Preservation of motor programs in paraplegics as demonstrated by attempted and imagined foot movements. Neuroimage 2008, 39, 383-394. [CrossRef] [PubMed] 
44. Castro, A.; Diaz, F.; van Boxtel, G.J. How does a short history of spinal cord injury affect movement-related brain potentials? Eur. J. Neurosci. 2007, 25, 2927-2934. [CrossRef] [PubMed]

45. Halder, P.; Curt, A.; Brem, S.; Lang-Dullenkopf, A.; Bucher, K.; Kollias, S.; Brandeis, D. Preserved aspects of cortical foot control in paraplegia. Neuroimage 2006, 31, 692-698. [CrossRef] [PubMed]

46. Mattia, D.; Cincotti, F.; Mattiocco, M.; Scivoletto, G.; Marciani, M.G.; Babiloni, F. Motor-related cortical dynamics to intact movements in tetraplegics as revealed by high-resolution EEG. Hum. Brain Mapp. 2006, 27, 510-519. [CrossRef] [PubMed]

47. Sabbah, P.; de, S.S.; Leveque, C.; Gay, S.; Pfefer, F.; Nioche, C.; Sarrazin, J.L.; Barouti, H.; Tadie, M.; Cordoliani, Y.S. Sensorimotor cortical activity in patients with complete spinal cord injury: A functional magnetic resonance imaging study. J. Neurotrauma 2002, 19, 53-60. [CrossRef] [PubMed]

48. Kokotilo, K.J.; Eng, J.J.; Curt, A. Reorganization and preservation of motor control of the brain in spinal cord injury: A systematic review. J. Neurotrauma 2009, 26, 2113-2126. [CrossRef] [PubMed]

49. Hou, J.M.; Sun, T.S.; Xiang, Z.M.; Zhang, J.Z.; Zhang, Z.C.; Zhao, M.; Zhong, J.F.; Liu, J.; Zhang, H.; Liu, H.L.; et al. Alterations of resting-state regional and network-level neural function after acute spinal cord injury. Neuroscience 2014, 277, 446-454. [CrossRef] [PubMed]

50. Oni-Orisan, A.; Kaushal, M.; Li, W.; Leschke, J.; Ward, B.D.; Vedantam, A.; Kalinosky, B.; Budde, M.D.; Schmit, B.D.; Li, S.J.; et al. Alterations in Cortical Sensorimotor Connectivity following Complete Cervical Spinal Cord Injury: A Prospective Resting-State fMRI Study. PLoS ONE 2016, 11, e0150351. [CrossRef] [PubMed]

51. Wrigley, P.J.; Gustin, S.M.; Macey, P.M.; Nash, P.G.; Gandevia, S.C.; Macefield, V.G.; Siddall, P.J.; Henderson, L.A. Anatomical changes in human motor cortex and motor pathways following complete thoracic spinal cord injury. Cereb. Cortex 2009, 19, 224-232. [CrossRef] [PubMed]

52. Freund, P.; Wheeler-Kingshott, C.A.; Nagy, Z.; Gorgoraptis, N.; Weiskopf, N.; Friston, K.; Thompson, A.J.; Hutton, C. Axonal integrity predicts cortical reorganisation following cervical injury. J. Neurol. Neurosurg. Psychiatry 2012, 83, 629-637. [CrossRef] [PubMed]

53. Min, Y.S.; Park, J.W.; Jin, S.U.; Jang, K.E.; Nam, H.U.; Lee, Y.S.; Jung, T.D.; Chang, Y. Alteration of Resting-State Brain Sensorimotor Connectivity following Spinal Cord Injury: A Resting-State Functional Magnetic Resonance Imaging Study. J. Neurotrauma 2015, 32, 1422-1427. [CrossRef] [PubMed]

54. Jin, B.; Su, Y.; Zhang, Y.; Wang, B.; Wang, H.; Wang, K.; Yan, T. Reorganization of brain cortex after spinal cord injury based on functional magnetic resonance imaging techniques. Zhonghua Yi Xue Za Zhi 2014, 94, 3082-3084. [PubMed]

55. Moxon, K.A.; Oliviero, A.; Aguilar, J.; Foffani, G. Cortical reorganization after spinal cord injury: Always for good? Neuroscience 2014, 283, 78-94. [CrossRef] [PubMed]

56. Chavakula, V.; Vasudeva, V.; Chi, J. Epidural Spinal Cord Stimulation for the Restoration of Balance and Gait Following Spinal Cord Injury. Neurosurgery 2016, 78, N19-N20. [CrossRef] [PubMed]

57. Gad, P.; Choe, J.; Nandra, M.S.; Zhong, H.; Roy, R.R.; Tai, Y.C.; Edgerton, V.R. Development of a multi-electrode array for spinal cord epidural stimulation to facilitate stepping and standing after a complete spinal cord injury in adult rats. J. Neuroeng. Rehabil. 2013, 10, 2. [CrossRef] [PubMed]

58. Minassian, K.; McKay, W.B.; Binder, H.; Hofstoetter, U.S. Targeting Lumbar Spinal Neural Circuitry by Epidural Stimulation to Restore Motor Function After Spinal Cord Injury. Neurotherapeutics 2016, 13, $284-294$. [CrossRef] [PubMed]

59. Vasudeva, V.S.; Abd-El-Barr, M.; Chi, J. Lumbosacral spinal cord epidural stimulation enables recovery of voluntary movement after complete motor spinal cord injury. Neurosurgery 2014, 75, N14-N15. [CrossRef] [PubMed]

60. Hawasli, A.H.; Chang, J.; Reynolds, M.R.; Ray, W.Z. Transfer of the brachialis to the anterior interosseous nerve as a treatment strategy for cervical spinal cord injury: Technical note. Glob. Spine J. 2015, 5, 110-117. [CrossRef] [PubMed]

61. Mackinnon, S.E.; Yee, A.; Ray, W.Z. Nerve transfers for the restoration of hand function after spinal cord injury. J. Neurosurg. 2012, 117, 176-185. [CrossRef] [PubMed]

(C) 2017 by the authors; licensee MDPI, Basel, Switzerland. This article is an open access article distributed under the terms and conditions of the Creative Commons Attribution (CC BY) license (http:/ / creativecommons.org/licenses/by/4.0/). 